Quality of practice

\section{The Quality of Practice Committee of the $\mathrm{RCPCH}$}

\section{N Mclntosh, J H Baumer}

\section{Update on the clinical effectiveness programme}

$\mathrm{F}$ ailure by doctors to incorporate strong research evidence into their clinical practice delays improvement in mortality and morbidity. The logo of the Cochrane collaboration ${ }^{1}$ (fig 1) shows the clear evidence of benefit from the randomised controlled trials of antenatal steroids in preterm labour available in 1982 if studies had been subject to meta-analysis. ${ }^{2}$ Antenatal steroids took over a decade after this point to be widely incorporated into obstetric practice despite the clear evidence that neonatal mortality and subsequent neurodevelopmental morbidity were reduced. ${ }^{3}$ Similarly suboptimal management was shown in a proportion of children with Kawasaki disease in the UK in $1990 .{ }^{4}{ }^{5}$ Only $60 \%$ received intravenous gammaglobulin, some in an inadequate dose, despite clear evidence of benefit from randomised controlled trials. A further example might be professional advice on the sleeping position for babies and therisk of cot death. ${ }^{6}$

There are a number of reasons for this. First, unless doctors are practising in a very narrow field there are just too many peer reviewed journals to read. In addition it is only by careful critical appraisal that the research evidence can be set in context of what is already known. This is a time consuming task, and requires a skill that not all doctors yet possess. There is also a genuine lack of knowledge in many medical areas, and one of the important functions of a guideline is to highlight research gaps. Advances in medical knowledge from additional research are also important in improving clinical management.

Clinical practice guidelines are "systematically developed statements to assist both practitioner and patient in decisions about appropriate health care for specific clinical circumstances". ${ }^{7}$ It is only through the systematic search for and appraisal of research evidence that truly "evidence based" recommendations can be produced. Clinical guidelines provide assistance for a number of decisions that together comprise a clinical pathway. Many evidence based clinical guidelines are supported by systematic reviews of research evidence.
A systematic review is "any summary that attempts to address a focused clinical question using methods designed to reduce the likelihood of bias", 8 Health technology assessments critically appraise all evidence on a specific intervention and give guidance for its use. Both clinical guidelines and systematic reviews can help to identify priorities for primary clinical research.

In 1996 the Royal College of Paediatrics and Child Health (RCPCH) mandated the Quality of Practice Committee (QPC) to:

"act to improve clinical practice by various means-including the production of guidelines. These guidelines will be evidence based, rigorously scrutinised by peer groups and should be eminently subject to audit."

The QPC oversees the College's clinical effectiveness programme, including clinical guidelines, the dissemination of systematic reviews, and clinical audit. Any statement about clinical practice made by or on behalf of the College is appraised by the QPC, which then makes recommendations to its Council. Effectively the QPC is the "guardian" of the College with regard to paediatric practice. The College's Health Services Committee undertakes a similar role for statements pertaining to the organisa-

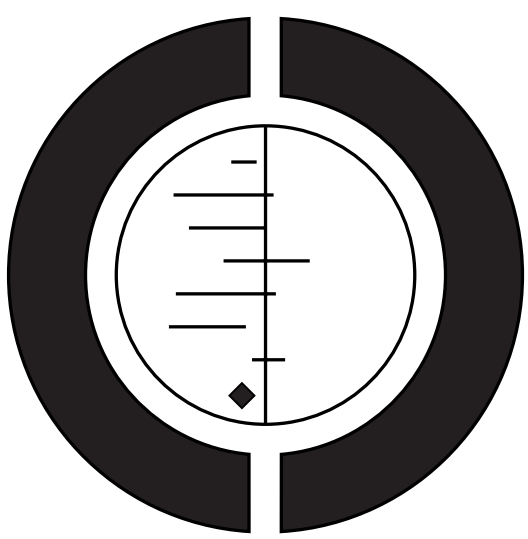

Figure 1 Logo of the Cochrane collaboration. tion or configuration of services However, any evidence based guidance on clinical practice may have implications for service delivery.

An evidence based clinical practice guideline ${ }^{9}{ }^{10}$ will contain a mixture of recommendations where there is supporting evidence and others where no research evidence exists. The College formally recognises three categories of statement about clinical practice (see table 1), and has different mechanisms for managing them.

The resources required to create a well produced evidence based clinical guideline are prodigious. The QPC has developed a procedure for appraising clinical guidelines $^{11}$ to ensure that only those produced according to best practice are given college endorsement. This involves checking the guideline methodology using the AGREE instrument ${ }^{12}$ and then reviewing all the recommendations supported by strong evidence alongside the original publications, to confirm that they accurately reflect the evidence.

The scope and clinical questions to be included are crucial if a guideline is to be useful to professionals and patients. It must be underpinned by a fully documented and rigorous literature review. Each relevant research study should be critically appraised and the level of evidence (1-5) documented using a system that defines a hierarchy of evidence relevant to the type of question. The grading system used for recommendations (A-D) likewise creates a hierarchy dependent on both the strength and applicability of the supporting evidence. It is therefore straightforward for readers to judge the strength of supporting evidence for each recommendation. Other important features of a clinical guideline include the involvement of all relevant professionals, and of children and their carers, the use of a formal consensus process (for example, Delphi) ${ }^{13}$ where evidence is lacking, piloting of the guideline, and the inclusion of audit criteria, written patient information, and educational material. A well produced evidence based guideline will also identify priorities for further research.

At present the QPC, for resource reasons, only appraises A and B recommendations. This is being addressed as sometimes $\mathrm{C}$ and $\mathrm{D}$ recommendations have even more clinical relevance and importance despite a weaker evidence base. The College Council gives final approval to endorse a clinical guideline. The college standards represent best practice but the approval process gives a measure of discretion so that while only well produced clinical guidelines are endorsed, the standards have not been set so high that they are unattainable. 
Table 1 College categories of clinical practice statements

\begin{tabular}{|c|c|c|}
\hline Nomenclature & Characteristics & College policy \\
\hline Evidence based guideline & $\begin{array}{l}\text { The composition of the guideline panel and its } \\
\text { processes are appropriate for the topic } \\
\text { There is a robust and well documented process for the } \\
\text { identification and synthesis of the evidence } \\
\text { - The guideline construction includes a transparent link } \\
\text { between the questions asked, the supporting evidence, } \\
\text { and the derivation of the recommendations } \\
\text { - May contain consensus statements (see below) }\end{array}$ & $\begin{array}{l}\text { May endorse through the recommendation of the Quality } \\
\text { of Practice Committee } \\
\text { A copy of the QPC appraisal is circulated via the College } \\
\text { quarterly newsletter } \\
\text { The guideline appraisal is posted on the clinical } \\
\text { effectiveness page of the College website, together with a } \\
\text { hotlink to the original guideline } \\
\text { - The topic may be showcased at the annual College } \\
\text { meeting in York } \\
\text { - Selected guidelines are summarised and reviewed in the } \\
\text { new Education and Practice supplement to Archives of } \\
\text { Disease in Childhood }\end{array}$ \\
\hline Consensus statement & $\begin{array}{l}\text { - A rigorous process has shown that there is no evidence } \\
\text { to answer the question } \\
\text { - Consensus takes account of the views of all involved in } \\
\text { the area including nurses, doctors, professions allied to } \\
\text { medicine, and parent/patient groups } \\
\text { - A specific methodology (e.g. Delphi), prevents the more } \\
\text { vociferous or articulate or those with specific issues } \\
\text { from unduly influencing the outcome } \\
\text { - The consensus process is transparent }\end{array}$ & - As for evidence based guidelines \\
\hline Practice statement & $\begin{array}{l}\text { - Absence of characteristics above } \\
\text { individuals and/or lacking clarity about the evidence } \\
\text { base used for its production }\end{array}$ & $\begin{array}{l}\text { - May be listed only by title on the website } \\
\text { "Practice statements have not been developed according } \\
\text { to RCPCH standards. There may not have been an } \\
\text { appropriate stakeholder base and the evidence base may } \\
\text { be incomplete. There may be unforeseen cost implications, } \\
\text { and there may be other approaches to clinical practice } \\
\text { that are equally or more appropriate. Members are asked } \\
\text { to note these qualifications when considering them with } \\
\text { respect to their own practice" }\end{array}$ \\
\hline
\end{tabular}

The production of clinical guidelines in itself does not change practice. ${ }^{14}$ In order to do so, the barriers to change need to be understood. A clear message should be promoted through multiple mechanisms (a "multi-faceted" approach), including championing by leaders, educational packages, and audit. Audit alone appears to be a weak driver for change, whereas championing by leaders in the field appears more effective (using "eminence based medicine" to promote "evidence based medicine"). Those developing a clinical guideline should therefore consider at the outset what are the potential barriers to implementation, and agree a supporting dissemination and implementation strategy that includes relevant supporting educational material for the profession and parents and children.

In the last five years the QPC has identified, appraised, and disseminated the appraisals of over 20 evidence based clinical guidelines on a wide variety of topics (table 2). Further guidelines are currently being appraised. The clinical guideline on chronic fatigue syndrome $(\mathrm{CFS} / \mathrm{ME})^{15}$ is the first one to be initiated and carried through entirely by the RCPCH. The Quality of Practice Committee remained independent of the guideline development group, and was therefore able to undertake the quality assurance without conflict of interest.
Not all the identified clinical guidelines have been endorsed in the appraisal process, however: one produced through the very reputable auspices of the Scottish Intercollegiate Guidelines Network (SIGN) contained significant discrepancies between the evidence cited and the recommendations, ${ }^{16}$ despite apparently appropriate guideline development methodology and despite consultation including the RCPCH. A revised version has been published by SIGN, ${ }^{17}$ but not appraised as the literature search was by then over five years old. Another guideline commissioned by the National Institute for Clinical Excellence (NICE) on eating disorders ${ }^{18}$ gave insufficient guidance on a number of important clinical issues for paediatric practice, including differential diagnosis and the management of complications. A third guideline on the management of urinary tract infections (from the American Academy of Pediatrics ${ }^{19}$ ) showed the importance of ensuring that the scope includes the appropriate outcomes. Although the $\mathrm{RCPCH}$ did endorse this guideline, the QPC appraisal commented that it did not address the link between childhood urinary tract infections, renal abnormalities, and long term outcome with or without treatment. ${ }^{20}$ Without this link, the recommendations for initial management of children following a urinary tract infection could not be considered valid. These examples illustrate some of the potential pitfalls of clinical guideline development, and justify the college's careful approach.

The Quality of Practice Committee, through strong links with SIGN, has for several years submitted suggestions for future guideline topics. NICE is now developing more evidence based clinical guidelines for a number of child health topics, and the QPC submits suggestions to its Advisory Committee for Topic Selection. The final decision about topic selection rests with the Secretary of State for Health and the Welsh Assembly. The College has also submitted priority topics for research identified through clinical guideline development to the National Coordinating Centre for Health Technology Appraisals.

The number of new paediatric clinical guidelines from NICE and SIGN will increase and other reputable sources (for example, the British Thoracic Society) are coming on-stream. Together with the existing evidence based guidelines, a formidable array of college endorsed guidelines should soon be a reality.

The QPC approach has meant that the RCPCH has been in a position to endorse more clinical guidelines, from a wide variety of sources, than would be the case if only college initiated 
Table 2 Clinical guidelines appraised and in receipt of college approval

\begin{tabular}{|c|c|c|}
\hline Guideline topic & Date & Organisation responsible \\
\hline Acute pain, recognition, and assessment & 2000 & Royal College of Nursing ${ }^{21}$ \\
\hline Asthma management† & Jan 2003 & British Thoracic Society, ${ }^{22}$ SIGN \\
\hline $\mathrm{ADHD}+$ & Jun 2001 & SIGN \\
\hline Breathing difficulties & Dec 2002 & Paediatric Accident \& Emergency Research Group ${ }^{23}$ \\
\hline Caries prevention in high risk children ${ }^{+}$ & Dec 2000 & SIGN \\
\hline CFS/ME & Dec 2004 & $\mathrm{RCPCH}$ \\
\hline Community acquired pneumonia & Dec 2002 & British Thoracic Society $^{24}$ \\
\hline Diarrhoea & Sep 2003 & Paediatric Accident \& Emergency Research Group ${ }^{25}$ \\
\hline Epilepsy & Sep 2004 & NICE \\
\hline Head injury & Jun 2003 & NICE \\
\hline Head injury, early management† & Sep 2000 & SIGN \\
\hline Infectious diseases exclusion periods & Apr 2001 & Health Protection Agency ${ }^{26}$ \\
\hline Milk banks, establishment and operation & Jan 2004 & UK Association of Milk Banks ${ }^{27}$ \\
\hline Neonatal RDS* & Nov 1998 & BAPM $^{28}$ \\
\hline Obesity prevention and management & Apr 2003 & SIGN \\
\hline Otitis media, acute and glue ear & Feb 2003 & SIGN \\
\hline Pleural infections & Feb 2005 & BTS \\
\hline Post-seizure management & Dec 2002 & Paediatric Accident \& Emergency Research Group ${ }^{29}$ \\
\hline Sore throat and tonsillectomy indications $†$ & Jan 1999 & SIGN \\
\hline Stroke in childhood, prevention and management & 2004 & Royal College of Physicians ${ }^{30}$ \\
\hline Sweat testing for CF & Nov 2003 & Association of Clinical Biochemists ${ }^{31}$ \\
\hline Urinary tract infection & Apr 1999 & American Academy of Pediatrics ${ }^{19}$ \\
\hline Type 1 diabetes $†$ & Nov 2001 & SIGN \\
\hline Type 1 diabetes & Jul 2004 & NICE \\
\hline
\end{tabular}

guidelines were endorsed. So, in what direction should the clinical guidelines programme be developing further? It has been suggested that the college might start producing "best practice guidelines or statements", without following a rigorous evidence based approach, so as to cover an even wider range of topics. This would run counter to the College's current policy, and it could not claim to be following best practice in relation to evidence based medicine. It would also undermine the College's position relating to poorly produced clinical guidelines submitted to it, and weaken the authority of well produced evidence based guidelines.

The other approach is to strengthen the college's mechanisms for promoting the messages from the clinical guidelines already being developed. NICE has until recently considered the implementation of its guidelines as outside its remit. The promotional material and mechanisms for disseminating its messages to clinicians are therefore usually weak, and the college could assist with this.

The guideline appraisals circulated to College members with the College newsletters now take the form of a summary of the clinical guidelines including the scope and all the recommendations. Only the A and B recommendations were previously included, but this has now changed. In future the College "standards for clinical guidelines" will include a stronger section on local implementation; this should include how to develop a local protocol/integrated care pathway and how to undertake an audit of compliance.
In addition, the College should take the lead in planning the launch of new guidelines, perhaps in collaboration with guideline developers including NICE. This could include the preparation of educational material, which would be likely to help their local implementation. The college needs to state more clearly to paediatricians what is expected of them when the college endorses a clinical guideline: unless they are adopted into practice the efforts of guideline developers are wasted.

In summary, the College's clinical effectiveness programme, overseen by the Quality of Practice Committee, has already endorsed a number of evidence based clinical guidelines, including its first in-house guideline on chronic fatigue syndrome (CFS/ME). ${ }^{15}$ It now needs to focus more directly on the local implementation and audit of well produced guidelines, and so help paediatricians achieve demonstrable improvements in the quality of delivered care.

Arch Dis Child 2005:90:888-891. doi: $10.1136 /$ adc. 2004.064253

\section{.....................}

\section{Authors' affiliations}

N McIntosh, University of Edinburgh, UK

J H Baumer, Derriford Hospital, Plymouth, UK

Correspondence to: Prof. N Mclntosh, Department of Child Life and Health, University of Edinburgh, 20 Sylvan Place, Edinburgh EH9 IUW, UK; neil.mcintosh@ed.ac.uk

Competing interests: none declared

\section{REFERENCES}

1 http://www.cochrane.org/logo/.
2 Crowley P, Chalmers I, Keirse M. The effects of corticosteroid administration before preterm delivery: an overview of the evidence from controlled trials. Br J Obstet Gynaecol 1990;97:11-25.

3 Chalmers I. Underuse of antenatal corticosteroids and future litigation. Lancet 1993;341:699.

4 Dhillon R, Newton L, Rudd PT, et al. Management of Kawasaki disease in the British Isles. Arch Dis Child 1993:69:631-6.

5 Levin M. Commentary. Arch Dis Child 1993;69:637-8.

6 Gilbert R. The changing epidemiology of SIDS. Arch Dis Child 1994;70:445-9.

7 Field MJ, Lohr KN, eds. Guidelines for clinical practice: from development to use. Washington, DC: National Academy Press, 1992.

8 Guyatt G, Rennie D. Users' guides to the medical literature. A manual for evidence-based clinical practice. American Medical Association, 2002.

9 Eccles M, Clapp Z, Grimshaw J, et al. North of England evidence based guidelines project: methods of guideline development. BMJ 1996;312:760-2.

10 A guideline developer's handbook. SIGN 50 http://www.sign.ac.uk/guidelines/fulltext/50/ index.html.

11 Royal College of Paediatrics and Child Health. Standards for development of clinical guidelines in paediatrics and child health, 2nd edn. London: RCPCH, 2001.

12 Cluzeau F. Appraisal of Guidelines for Research and Evaluation (AGREE) Instrument. http:// www.agreecollaboration.org/.

13 Jones J, Hunter D. Qualitative Research: Consensus methods for medical and health services. BMJ 1995;311:376-80.

14 NHS Centre for reviews and dissemination. Getting evidence into practice. Effective Health Care, 1999;1. http://www.york.ac.uk/inst/crd/.

15 Royal College of Paediatrics and Child Health Evidence based guideline for the management of CFS/ME (chronic fatigue syndrome/myalgic encephalopathy) in children and young people. London: RCPCH, 2004. www.rcpch.ac.uk/.

16 RCPCH guideline appraisal. Evidence-based guidelines for the safe sedation of children undergoing diagnostic and therapeutic procedures. http://www.rcpch.ac.uk/ publications/clinical docs/ Safe_Sedation\%20.pdf.

17 SIGN. Evidence-based guidelines for the safe sedation of children undergoing diagnostic and therapeutic procedures. Scottish Intercollegiate 
Guidelines Network, revised 2004. http:// www.sign.ac.uk/pdf/sign58.pdf.

18 The British Psychological Society \& The Royal College of Psychiatrists. Eating disorders. Core interventions in the treatment and management of anorexia nervosa, bulimia nervosa, and related eating disorders. National collaborating centre for mental health, commissioned by NICE. The British Psychological Society \& The Royal College of Psychiatrists, 2004. http:// www.nice.org.uk.

19 American Academy of Pediatrics Committee on Quality Improvement. Practice parameter: the diagnosis, treatment, and evaluation of the initial urinary tract infection in febrile infants and young children. Pediatrics 1999; 103:843-52.

20 RCPCH. Guideline appraisal. The diagnosis, treatment, and evaluation of the initial urinary tract infection in febrile infants and young children. http://www.rcpch.ac.uk/publications/ clinical_docs/UTI_guideline.pdf.

21 The recognition and assessment of acute pain in children. Royal College of Nursing. http:// www.rcn.org.uk/publications/pdf/guidelines/ cpg_contents.pdf

22 http://www.brit-thoracic.org.uk/index.php.

23 www.pier.shef.ac.uk.

24 British Thoracic Society Standards of Care Committee. Guidelines for the management of community acquired pneumonia in childhood. Thorax 2002;57(suppl 1). http://www. brit-thoracic.org.uk.

25 Armon K, Stephenson T, MacFaul R, et al. An evidence and consensus based guideline for acute diarrhoea management. Arch Dis Child 2001;85:132-42.

26 Richardson M, Elliman D, Maguire $\mathrm{H}$, et al. Evidence base of incubation periods, periods of infectiousness and exclusion policies for the control of communicable diseases in schools and preschools. Paediatr Infect Dis J 2001:20:380-91.

27 http://www.ukamb.org/.

28 http://www.bapm.org/

29 Armon K, Stephenson TJ, MacFaul R, et al. An evidence and consensus based guideline for the management of a child after a seizure. Emerg Med J 2003;20:13-20.

30 Ganesan V (Chair), Paediatric Stroke Working Group. Stroke in childhood. Clinical guidelines for diagnosis, management and rehabilitation. London: Royal College of Physicians, 2004

31 National Guidelines for the Performance of the Sweat Test for the Investigation of Cystic

Fibrosis. Association of Clinical Biochemists. http://www.acb.org.uk/Guidelines/sweat.htm.

\section{IMAGES IN PAEDIATRICS}

\section{BCG reactivation: a useful diagnostic tool even for incomplete Kawasaki disease}

A 6 week old child of Chinese origin presented with a history of persistent fever for three days. She was very irritable and had bright red lips and few maculopapular spots on the trunk. She did not have any significant cervical lymphadenopathy, but did have red eyes. In view of the age a full septic screen was performed and intravenous antibiotic was started. Investigations revealed a raised white blood cell count, C reactive protein, erythrocyte sedimentation rate, and liver enzymes, but normal chest $x$ ray, cerebrospinal fluid, and urine. She continued to have a very high spiking temperature even at 48 hours despite negative blood culture. Subsequently marked redness with some induration was noticed around the BCG site.

Due to the presence of fever for over five days, conjunctivitis, red lips, and irritability, incomplete Kawasaki disease was postulated. This hypothesis was further strengthened by the development of erythema around the BCG scar.

The child was started on intravenous immunoglobulin in accordance with a recent recommendation of the American Heart Association. ${ }^{1}$ Fever subsided within 36 hours and the erythema around the BCG site disappeared. Her initial echocardiogram was normal and she is under cardiac follow up.

Any child with irritability and persisting fever ( $\geqslant 5$ days) not responding to antipyretics should be suspected to have Kawasaki disease. All criteria need not be fulfilled; incomplete Kawasaki disease may be present. ${ }^{1}$ In view of the reported higher incidence of coronary involvement in infancy, ${ }^{2}$ an early diagnosis and prompt treatment are essential. Erythema at the site of BCG inoculation is rare, but it is a specific sign of Kawasaki disease ${ }^{3}$ and hence can be used as a tool for an early diagnosis.

Children have been diagnosed early by looking at the BCG scar on admission. ${ }^{4}$ This should be particularly useful in communities where BCG vaccination is universal. This phenomenon has been hypothetically ascribed to

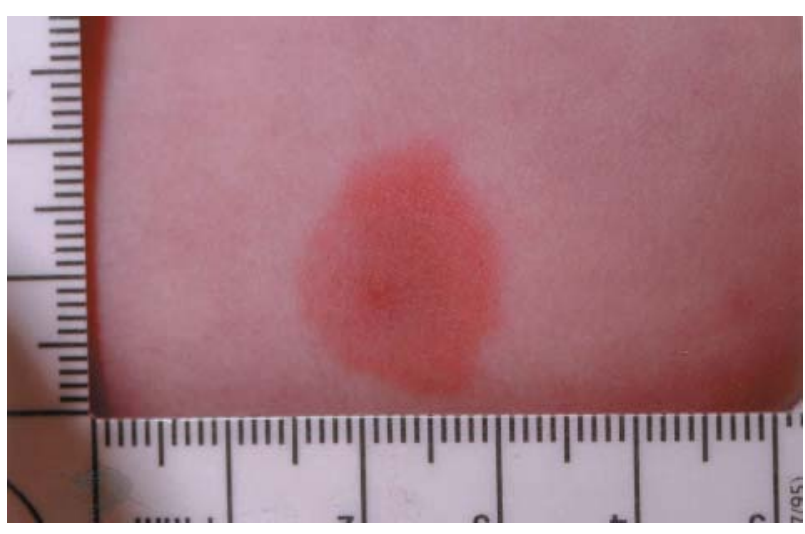

Consent was obtained for publication of this figure.

cross-reactivity between mycobacterial heat shock protein (HSP) 65 and human homologue HSP 63.5

R Sinha, T Balakumar

St Peter's Hospital, Chertsey, UK; rajivsinha_in@yahoo.com

Competing interests: none declared

\section{References}

1 Newburger J, Takahashi M, Gerber M, et al. Diagnosis, treatment and long term management of Kawasaki Disease. Circulation 2004;1 10:2747-71.

2 Burns JC, Wiggins JW Jr, Toews WH, et al. Clinical spectrum of Kawasaki disease in infants younger than 6 months of age. J Pediatr 1986;109:759-63.

3 Plantin P, Blayo M, Dupre D, et al. BCG reactivation: a rare but specific sign of Kawasaki disease. Presse Med 1998;27:716.

4 Cheng YW. HK Pract 2003;25:127-33.

5 Sireci G, Dieli F, Salerno A. T cells recognize an immunodominant epitope of heat shock protein 65 in Kawasaki disease. Mol Med 2000;6:581-90. 